\title{
BAZI HERBİVOR BÖCEKLER HAKKINDA BIYYOLOJIKK GÖZLEMLER
}

\author{
Seda Emel TEK*, Zühal OKYAR \\ Trakya Üniversitesi, Fen Fakültesi, Biyoloji Bölümü, Balkan Yerleşkesi, 22030, Edirne \\ *Corresponding author: e-mail: sedaemeltek@gmail.com
}

\begin{abstract}
Özet: 2013-2016 döneminde Trakya Bölgesi’nde yapılmış arazi çalışmaları sırasında örneklenen herbivor özellikteki Archips rosana (Linnaeus) (Lepidoptera: Tortricidae), Melitaea didyma (Esper) (Lep.: Nymphalidae), Melitaea cinxia (Linnaeus) (Lep.: Nymphalidae), Allophyes oxyacanthae (Linnaeus) (Lep.: Noctuidae), Aporia crataegi (Linnaeus) (Lep.: Pieridae), Periclistus brandtii (Ratzeburg) (Hymenoptera: Cynipidae), Lymantria dispar (Linnaeus) (Lep.: Erebidae) ve Mustha spinosula (Lefèbvre) (Hemiptera: Pentatomidae)'nin biyolojik bazı özellikleri laboratuvar ortamında gözlenmiş ve bulgular değerlendirilmiştir. A. rosana ve $M$. didyma larvalarında karnivor ve kanibalizm davranışları, A. oxyacanthae ergin dişisinin partenogenez yolu ile yumurta üretmesi, M. spinosula ergininin L. dispar larvaları ile olan birlikteliğinde gösterdiği savunma/predatör davranışı ve $P$. brandtii'nin Pyrus communis (Linnaeus) bitkisi ile olan birlikteliği ilk kez gözlenen durumlar olmuştur. Ayrıca Melitaea cinxia larvasından Erycia festinans (Meigen) (Diptera: Tachinidae) parazitoiti elde edilmiş olup, $E$. festinans türü Türkiye için yeni bir dipter kaydı olmuştur. E. festinans $M$. cinxia ile olan birlikteliği Türkiye için yeni bir parazitoit-konak kaydıdır.
\end{abstract}

Anahtar kelimeler: Böcek davranışı, karnivor, kanibalizm, predasyon, partenogenez, savunma, parazitoit.

\section{Biological Observations on Some Herbivorous Insects}

\begin{abstract}
Some biological characteristics of the herbivorous Archips rosana (Linnaeus) (Lepidoptera: Tortricidae), Melitaea didyma (Esper) (Lep.: Nymphalidae), Melitaea cinxia (Linnaeus) (Lep.: Nymphalidae), Allophyes oxyacanthae (Linnaeus) (Lep.: Noctuidae), Aporia crataegi (Linnaeus) (Lep.: Pieridae), Periclistus brandtii (Ratzeburg) (Hymenoptera: Cynipidae), Lymantria dispar (Linnaeus) (Lep.: Erebidae) and Mustha spinosula (Lefèbvre) (Hemiptera: Pentatomidae) obtained from Thrace Region during field studies in the period of 2013-2016 were monitored in laboratory conditions and the observations were evaluated. The carnivorous behaviour of $A$. rosana and $M$. didyma larvae, egg production by adult females of $A$. oxyacanthae through parthenogenesis, the defense/predatory behaviour of $M$. spinosula adults on $L$. dispar larvae and the association of $P$. brandtii with Pyrus communis (Linnaeus) plant are the observations reported for the first time. Furthermore, from Melitaea cinxia larva, the parasitoid Erycia festinans (Meigen) (Diptera: Tachinidae) emerged. E. festinans is a new record for Diptera fauna of Turkey. Correspondingly, M. cinxia and E. festinans is a new host-parasitoid association for Turkey.
\end{abstract}

Key words: Insect behaviour, carnivore, cannibalism, predation, parthenogenesis, defence, parasitoid.

\section{Giriş}

Böcekler tür sayısı bakımından dünya üzerinde yaşayan tüm organizmaların yarısından daha fazla bir çoğunluğa sahiptir. Dünyadaki toplam biyokütlenin en geniş parçasını oluşturan bitkiler üzerinden besinini karşılayan herbivor böcekler ise bu yığının yaklaşık yarısını oluştururlar. $\mathrm{Bu}$ yoğun çeşitlilik, türlerin etkileşimde olduğu çevresi ile de birleşince kompleks bir trofik ağı beraberinde getirmektedir. Canlılar arasındaki etkileşimler komünite dinamiklerini etkilemekte ve aynı zamanda da komünite dinamikleri tarafindan bu ilişkiler etkilenebilmektedir (Schoonhoven ve ark. 2005, Stam ve ark. 2014). Böcekler arasındaki etkileşimlere dair öğrenilecek her bilgi (doğal düşmanlar, rekabet, konukçu seçimleri, davranışsal gözlemler ve bunların altında yatan kimyasal bilgiler, bitki bileşikleri vb.), biyokontrol çalışmalarından, bitki, böcek ve doğal alanların korunmasına kadar birçok alanda faydalı olacaktır (Tunca ve ark. 2011).

$\mathrm{Bu}$ çalışmada 2013-2016 yılları arasında Trakya Bölgesi'nde yürütülen farklı çalışmalar sırasında bazı herbivor böcekler hakkında yapılan gözlemler raporlanmıştır. Çalışmada gözlemlenen bu durumlar, mevcut literatür ile karşılaştırılarak yorumlanmıştır.
Materyal ve Metot
Trakya Bölgesi'nde, 2013-2016 yılları arasında vejetasyon dönemlerinde yapılan arazi çalışmaları sirasinda toplanan larva, pupa ve ergin evrelerindeki herbivor böcekler, üzerinde bulunduğu bitki ile birlikte laboratuvara getirilmiş ve yetiştirilmiştir. Böceklerin arazide toplama aşaması, bitkiyi silkeleme ve gözle kontrol metotları ile yapılmış olup, laboratuvarda 
yetiştirme aşaması ise içerisinde toplandığı bitkiyi içeren $10 \times 10 \mathrm{~cm}$ ve $10 \times 15 \mathrm{~cm}$ ebatlarında üzeri gazlı bez ile örtülü plastik kaplar içerisinde gerçekleştirilmiştir. Yetiştirme süresince laboratuvar sıcaklığ $27^{\circ} \mathrm{C}$ ve nem $\% 52$ seviyesinde tutulmuştur. Bu süreçte böcekler gözlemlenmiş ve farklı davranışlar not edilmiştir. Yetiştirme kaplarında ergin hale ulaşan böcekler tayin edilmiş olup, Trakya Üniversitesi Biyoloji Bölümü Entomoloji Müzesi'nde muhafaza edilmektedir.

\section{Sonuçlar ve Tartışma}

\section{$\underline{\text { Archips rosana (Linnaeus) (Lepidoptera: Tortricidae) }}$}

A. rosana'nın ait olduğu Tortricidae familyası, türlerin birçoğu larva halinde iken konukçu olduğu bitkilerin yapraklarını bükerek kendisine bir yuva oluşturduğu için "yaprak bükenler" olarak adlandırılmaktadır. Larvalar beslenme ve pupa oluşumu evrelerini büktükleri bu yaprak yuvalarda tamamlamaktadır. A. rosana yaprakların yanı sıra konak bitkinin çiçeklerinden, tomurcuklarından ve ufak meyvelerinden de beslenmesi ürün kayıplarına yol açmakta ve meyve verimini düşürmektedir (Meijerman ve Ulenberg 2000).

A. rosana, Rosaceae familyası dahil bir çok bitki familyası üzerinden beslenen polifag bir türdür. Türün larva aşamasında üzerinde beslendiği bilinen ve Palearktik Bölge'de dağılım gösteren konak bitkiler Aceraceae, Betulaceae, Caprifoliaceae, Cornaceae, Ericaceae, Fabaceae, Fagaceae, Grossulariaceae, Juglandaceae, Pinaceae, Rhamnaceae, Rosaceae (Crataegus sp., C. douglasii Lindl, Malus sp., $M$. domestica Borkhausen, M. sylvestris Miller, Prunus sp., $P$. armeniaca Linnaeus, $P$. amygdalus Batsch, $P$. avium Linnaeus, $P$. ceracus Linnaeus, $P$. domestica Linnaeus, $P$. mahaleb Linnaeus, $P$. persica (Linnaeus), $P$. spinosa Linnaeus, $P$. virginiana Linnaeus, Pyrus sp., $P$. communis Linnaeus, Ribes aureum Pursh, R. rubrum Linnaeus, Rosa sp., $R$. canina Linnaeus, Rubus sp., $R$. parviflorus Nuttall, $R$. rugosa Smith, $R$. idaeus Linnaeus), Rutaceae, Salicaceae ve Ulmaceae familyalarına dahildir (Özdemir ve ark. 2005, Brown ve ark. 2008, Polat ve Tozlu 2010). Çalışma sırasında A. rosana bireyleri arazide Pyrus communis (Rosaceae) üzerinden larva halinde iken toplanmış ve bu bitki ile beslendiği laboratuvarda gözlenmiştir. Bununla birlikte larvaların karnivor beslenme davranışı gösterdiği de laboratuvar şartlarında gözlenen bir durum olmuştur. Tortricidae familyasına ait larvaların 2 farklı karnivor beslenme davranışı gösterdiği saptanmıştır.

Bir örnekleme kutusunda, iki A. rosana larvası arasında yamyamlık (kanibalizm) durumu gözlemlenmiştir. Şekil 1'de beyaz çember içerisinde gösterilen larvanın, diğer larvanın abdomeninin ucunu 1sirarak vücut sıvısını çıkarttı̆̆ı ve sıvı ile beslendiği görülmüştür.

Bir diğer örnekleme kutusunda ise iki A. rosana larvasının bir tanesinden Tachinidae parazitoidinin çıkıp fiçı pupa ördüğü ve bu pupanın bir kısmının aynı kutu içindeki sağlıklı olan diğer $A$. rosana larvası tarafından 1sırılmış olduğu görülmüştür (Şekil 2). Birkaç gün sonra sağlıklı olan larva pupa oluşturmuş ve metamorfoz süresi sonunda pupadan ergin birey çıkmıştır.

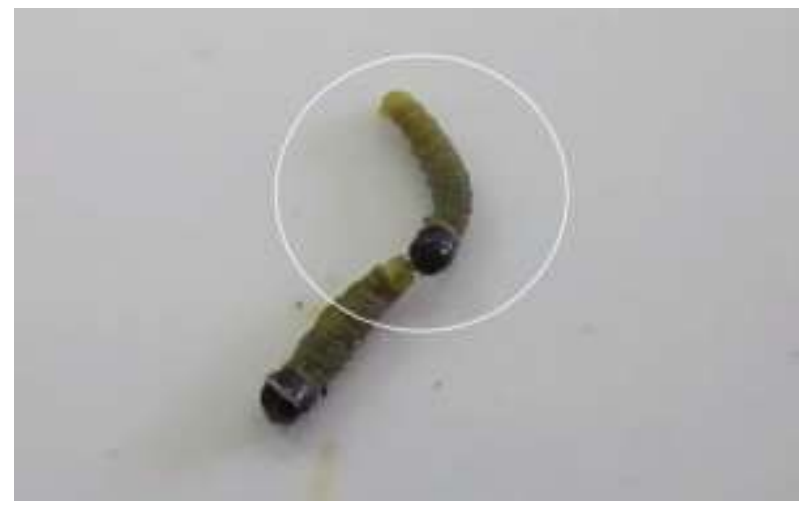

Şekil 1. Archips rosana larvaları arasında yamyamlık.

Sonuç olarak, her iki durumda da, normal şartlarda herbivor beslendiği bilinen $A$. rosana, muhtemelen ortamdaki besin sıkıntısı nedeniyle hem kendi türünden bir larva üzerinde hem de kendi türünü parazitize etmiş olan bir dipter üyesinin pupası üzerinden karnivor olarak beslenmiştir.

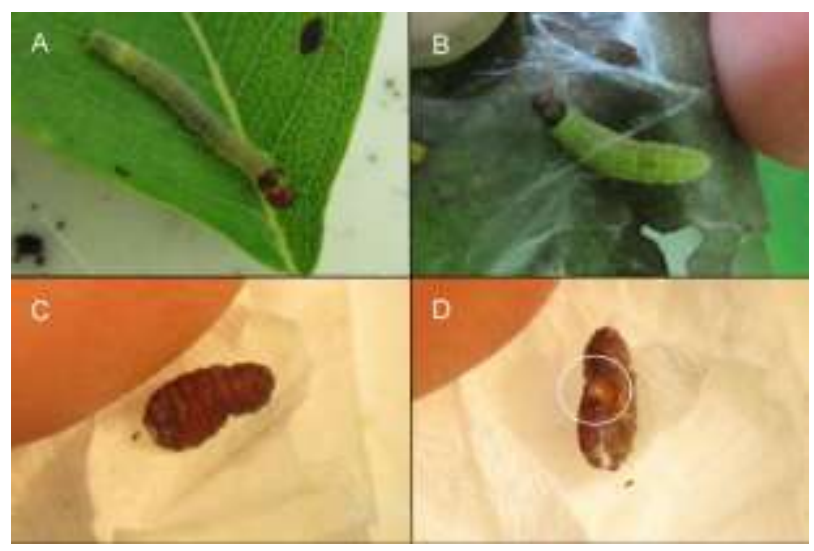

Şekil 2. Archips rosana larvasının Tachnidae pupası üzerinde predasyonu: (A) Predasyonu yapan sağlıklı A. rosana larvası. (B) Parazitoidlenmiş A. rosana larvası. (C), (D) Parazitize A. rosana larvasından çıkmış Tachinidae larvasının fiçı pupası (sağlıklı larva tarafından 1sırılan bölge beyaz çember içine alınmıştır).

Besin kaynağı yetersiz olduğunda görülebilen yamyamlık, bunu gerçekleştiren canlının yaşam süresini uzatabilir ya da yüksek protein içeren bu besinlerin tüketimi ile yamyamın gelişim ve üreme başarısını arttırabilir (Joyner ve Gould 1985, Kakimoto ve ark. 2003, Richardson ve ark. 2010, Wang ve Daane 2014). A. rosana hakkında literatürde karnivor ya da yamyamlık açısından bir bilgiye ulaşılamamıştır. Bununla birlikte, farklı Archips ya da Tortricidae türlerinin larvaları hakkında yamyamlık bulguları mevcuttur (Smirnoff 1967, Sullivan ve ark. 2011, Wang ve Daane 2014). Wang ve Daane (2014)'in çalışmasında, araştırılan bir tortricid türünde (Choristoneura rosaceana (Harris)), türün larvasının sağlıklı olan larvadan ziyade, bir braconid türü tarafından parazite olmuş larvaya yönelik bir yamyamlık davranışı gösterdiği bildirilmiştir. 
Bu çalışmada A. rosana hakkında gözlemlenen iki farklı karnivor beslenme durumu da besin yetersizliğinin olduğu bir periyotta meydana gelmiştir. Besin yetersizliği de bir taraftan A. rosana larvaları arasında yamyamlığı; diğer bir taraftan da A. rosana herbivorunun, türdeşinden çıkmış dipter parazitoidinin pupasına yönelik gerçekleştirdiği predatörlük davranışını tetiklemiş olabilir.

\section{Melitaea didyma (Esper) (Lepidoptera: Nymphalidae)}

$\mathrm{Bu}$ kelebek türünün larvaları, Plantago sp. (Plantaginaceae); Valeriana sp. (Valerianaceae); Antirrhinum sp., Digitalis sp., Linaria sp., Verbascum sp., Veronica sp. (Scrophulariaceae); Stachys sp. (Labiatae); Centaurea sp.; Trifolium sp. (Papilionaceae) türlerine dahil olan bazı bitki türlerini besin olarak kullanmaktadır (Tolman 1997, Baytaş 2008, BRC 2011).

Araziden toplanmış iki adet $M$. didyma larvası aynı örnekleme kabı içerisinde yetiştirilmiştir. Larvalardan bir tanesi pupaya girmiş ve birkaç günün sonunda diğer larvanın ortamdaki besin yetersizliğinden dolayı aynı kapta bulunan pupa halindeki türdeşi üzerinden beslendiği görülmüştür (Şekil 3). Yamyam larva sonrasında pupasını oluşturmuş fakat muhtemelen ortam şartlarından ötürü pupadan ergin olarak çıkamamıştır. $M$. didyma larvasının karnivor ya da yamyam beslenmesi hakkında bir bilgiye literatürde rastlanmamıştır. Bununla birlikte bazı araştırmalarda, türün ait olduğu altfamilyaya (Melitaeinae) ait bazı türlerde yumurta ve larva yamyamlığının bulunduğu belirtilmiştir (Clark ve Faeth 1998, Kuussaari ve ark. 2004).

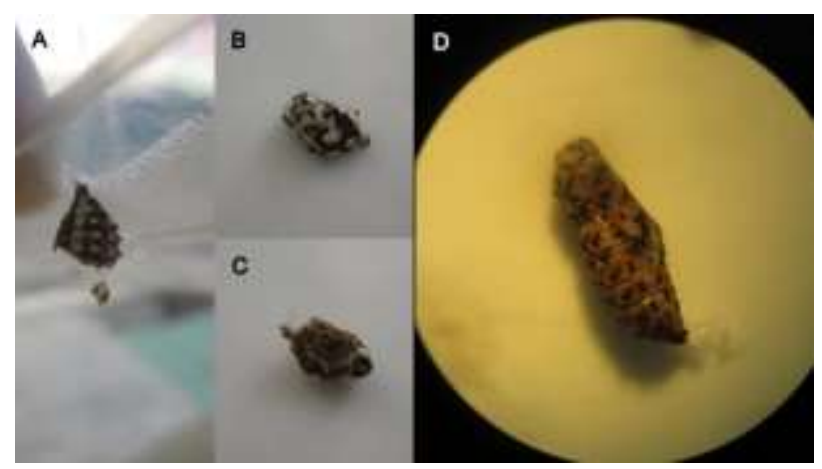

Şekil 3. Melitaea didyma larvasının pupa üzerindeki yamyamlığı: (A), (B), (C) Yamyamlığa uğramış olan pupanın parçaları. (D) Yamyam larvanın beslenmeden sonra oluşturduğu pupa.

Melitaea cinxia (Linnaeus) (Lepidoptera: Nymphalidae) ve Erycia festinans (Meigen) (Diptera: $\underline{\text { Tachinidae) }}$

Melitaea cinxia türüne ait larval bireyler Plantago lanceolata (Plantaginaceae) yaprakları üzerinde gregar halde beslenirken gözlemlenmiş ve larvalar besin bitkileri ile toplanarak laboratuvarda yetiştirilmiştir. Larva aşamasında lepidopter bireylerin bir tanesinden tachinid larvasının çıkış yapıp konak larva yakınında kendi pupasını oluşturmuş olduğu gözlenmiştir. Ergin halde pupasından çıkan dipter, Erycia festinans olarak teşhis edilmiştir.
Erycia tachinid cinsinin, Melitaeini lepidopterleri üzerinde spesyalist bir parazitoit olduğu düşünülmektedir. Ayrıca Melitaeini'ye dahil olan Melitaea spp. ve Euphydryas spp.'ye ait türleri parazitlediği iyi bilinmektedir. (Herting 1960, Van Nouhuys ve Hanski 2004).

Ülkemizde yapılan çalışmalarda Erycia cinsine ait sadece fascinata türü tespit edilmiş olup; bu tachinid türünün, Verbascum sp. (Scrophulariaceae) üzerinden beslenen Melitaea didyma türünü konak olarak kullandığ kaydedilmiştir (Bayram ve Kara 1998).

Erycia festinans dipter türünün ülkemizde varlığına dair yayınlanmış bir kayıt bulunmamaktadır. Bununla birlikte E. festinans'in Bulgaristan ve Yunanistan'daki varlığı, türün Türkiye'de de bulunmasını beklenir kılmaktadır (Fauna Europaea 2014).

Dünyada yapılan çalışmalarda Erycia festinans'a ait bireylerin Avrupa ve Sibirya coğrafik bölgelerinde, larva evresinde olan Melitae cinxia ve Melitaea didyma türlerini konak olarak kullandığı tespit edilmiştir (Ford ve ark. 2000, Wahlberg ve ark. 2001, Van Nouhuys ve Hanski 2004). Türkiye'de ise hem Erycia festinans tachinidinin, hem de türün Melitae cinxia ile olan konak ilişkisinin ülkemizdeki varlığı bu çalışma ile ilk kez bulgulanmıştır.

Allophyes oxyacanthae (Linnaeus) (Lepidoptera: Noctuidae)

Larva aşamasında iken Prunus spinosa Linnaeus (Rosaceae) üzerinden toplanan larva laboratuvar şartlarında beslenerek yetiştirilmiştir. Ergin hale gelen dişi bireyin, yetiştirme kabının tavanına partenogenez ile yumurtalar bırakmış olduğu görülmüştür. Yumurtalar larva oluşumu için bekletilmiş fakat herhangi bir larva çıkışı olmamıştır. Literatürde A. oxyacanthae türünün partenogenez ile yumurta ürettiği hakkında bir bilgiye ulaşılamamıştır. Partenogenetik üreme, eşeysel üremeye uygun olmayan ortam şartlarında ya da erkeklerin sayıca az olduğu durumlarda türün neslinin devamlılığını sürdürme açısından oldukça faydalıdır. Ancak partenogenetik üremenin sürekliliği genetik çeşitliliği sınırlayacak ve türün kendileşmesini sağlayacaktır. $A$. oxyacanthae türünün partenogenetik üremeyi hangi çevresel tehdit altında gerçekleştirdiği konusu detaylı bir çalışmayı gerektirmektedir.

Aporia crataegi (Linnaeus) (Lepidoptera: Pieridae), Periclistus brandtii (Hymenoptera: Cynipidae)

A. crataegi larvalar1, yuvası ile beraber Pyrus communis Linnaeus (Rosaceae) bitkisinden alınarak laboratuvara getirilmiştir. Yuva içerisine bakıldığında, Şekil 4'de gösterildiği üzere, 4 beyaz parazitoid kozası ve kozalar etrafinda az hareket eden A. crataegi larvaları fark edilmiştir. Beyaz kozalardan Periclistus brandtii türüne ait ergin bireyler çıkmıştır. Bununla birlikte $P$. brandtii gal içlerinde yerleşimci konumda bulunarak yaşamını sürdüren bir türdür ve gal dışında bir yerde yerleşimci olduğuna dair bir bilgi bulunmamaktadır. 


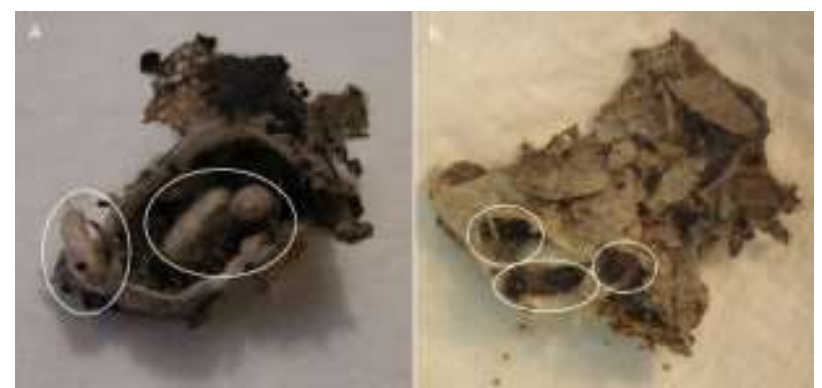

Şekil 4. Pyrus communis üzerinde bulunan Aporia crataegi yuvasında gözlenmiş Periclistus brandtii cynipid kozaları: (A) Yuva içerisinde gözüken beyaz renkteki $P$. brandtii kozaları (kozalar beyaz çember içine alınmıştır). (B) Başka bir açıdan yuva içerisinde gözüken A. crataegi larvaları (larvalar beyaz çember içine alınmıştır).

Cynipid gal yerleşimcileri, Periclistus brandtii türünde olduğu gibi, gal oluşturma yetilerini yitirmiş olmalarına rağmen, gal arıları gibi fitofag böcektirler. Gal yerleşimcilerinin larvaları gal içerisindeki odacıklarda ya da galin dış dokularında beslenip büyür ve gelişebilir. Ĕger yerleşimci türün gal içerisindeki birey sayısı çok fazla olursa, ortamdaki diğer gal arılarına toksik etki yapıp onları öldürebilirler. Periclistus türleri, Rosa türlerinde gal yapan Diplolepis sp. gallerinde yerleşimci konumundadır (Ronquist 1994, Katılmış ve Kıyak 2011). Periclistus larvaları yaz boyunca gal odacıklarında bulunur, kışı pupa öncesi evrede geçirir ve baharda da pupa olurlar; sonrasında ergin olarak gallerden çıkar, çiftleşir ve yumurtlamak için olgunlaşmamış bir gal seçerler (Shorthouse 1973, 1993, Shorthouse ve Leggo 2002, Katılmış ve Kıyak 2011).

Periclistus cinsinin ait olduğu Synergini cynipidleri, Rosa sp. üzerindeki Cynipidae (Hymenoptera) türlerinin sebep olduğu gallerin dışında ayrıca Quercus sp. üzerindeki Cecidomyiidae (Diptera) türlerinin oluşturduğu gallerde yerleşimci olabilmektedir (Katılmış ve Azmaz 2015). Cecidomyiidae taksonuna ait kimi türlerin ayrıca Pyrus communis bitkisinde de yaprakları şişirip bükerek gal oluşumuna neden olabildiği literatürde belirtilmiştir (Skuhravá ve ark. 2007).

Bu çalışmadaki gözlemde, Cecidomyiidae türlerinden birisinin Pyrus communis üzerinde oluşturduğu gal içerisine Periclistus brandtii bireyi yumurtalarını bırakmış olabilir. Bu kompleksin yakınlarına da Aporia crataegi'nin yumurta bırakması (veya türlerin biyolojik zamanına göre tam tersi), sonrasında da lepidopter yumurtalarının çatlayıp ilk instarların bu bölgelerden beslenip yuvayı bu gal etrafina örmeleri, ya da bu galde saklanmaları böyle bir sonuca neden olmuș olabilir.

Bununla birlikte Periclistus türleri Rosa sp. (Rosaceae) üzerindeki Diplolepis spp. ve Liebelia sp. gallerinde; Smilax sp. (Smilacaceae) üzerindeki Diastrophus smilacis Ashmead gallerinde gözlendiği literatürde bildirilmiştir (Penzes ve ark. 2012). Periclistus türlerinin Pyrus communis türü ya da cinsi ile bir ilişkide olduğuna dair bilgiye daha önceki literatür çalışmalarında rastlanmamıştır. Bu çalışmada gözlemlenen durumda ise her olas1l1kta Periclistus brandtii türünün Pyrus communis ile bir birlikteliği bulunduğu sonucuna varılmaktadır ve bu yeni bir gözlem bulgusudur.

Lymantria dispar (Linnaeus) (Lepidoptera: Erebidae) ve Mustha spinosula (Lefèbvre) (Hemiptera: Pentatomidae)

Cydonia oblonga Miller (Rosaceae) üzerinden toplanan Mustha spinosula ergin bireyleri (2 birey), aynı zamanda aynı bitkiden toplanmış olan Lymantria dispar larvaları ( 5 birey) ile beraber laboratuvar koşullarında 1 gün aynı örnekleme kutusu içerisinde bırakılmıştır. Bu süre sonunda kutu kontrol edildiğinde tüm lepidopter larvalarının ölüm katılığında olduğu (ölmüş olduğu) ve kutu içerisinde kahverengimsi-kırmızımsı lekeler bulunduğu görülmüştür.

L. dispar türü pek çok ülkede ağaç ve çalılara zarar derecesi fazla olan polifag ve istilacı bir türdür (Alford 2012). Kuzey yarım kürede Rosaceae familyasına dahil pek çok türü de içeren, 300'den fazla bitki ile beslenmektedir (GOERT 2003). Türün Palearktik Bölge'de larva aşamasında beslendiği bilinen bitkiler: Aceraceae, Anacardiaceae, Betulaceae, Fabaceae, Fagaceae, Juglandaceae, Myricaceae, Oleaceae, Pinaceae, Polygonaceae, Rosaceae "(Crataegus sp., C. monogyna Jacquin, Cydonia sp., Malus sp., M. pumila Miller, Prunus sp., P. spinosa Linnaeus, P. domestica Linnaeus, Pyrus sp., P. communis Linnaeus, Rosa sp., Rubus sp.)" Salicaceae, Tamaricaceae, Tiliaceae ve Ulmaceae taksonlarına dahildir (Lechowicz ve Mauffette 1986, Robinson ve ark. 2010, BRC 2011, Molet 2012).

M. spinosula türünün Aquifoliaceae, Cupressaceae, Fabaceae, Fagaceae, Juglandaceae, Oleaceae, Platanaceae, Rosaceae (Crataegus sp., C. azarolus Linnaeus, Pirus malus Linnaeus, Prunus sp., $P$. amygdalus Batsch) ve Salicaceae familyaları üzerinden beslendiği ya da bu bitkiler üzerinde bulunmuş olduğu bilgisi literatürde mevcuttur (Lodos ve ark. 1998, Kanat ve Akbulut 2005, Rider 2015).

M. spinosula türünün ait olduğu Pentatomidae familyası, rahatsız edildiğinde salgıladığı kötü kokuları ile bilinmektedir. Krall ve ark. (1999)'nın çalışmasında Cosmopepla bimaculata (Thomas) pentatomidinin salgıladığ kimyasalların predatörlerine karşı kullanılma durumları test edilmiștir. Türün genellikle çok rahatsız edilmedikçe bu kokuyu kullanmadan yürüyerek uzaklaştığı, ya da, ancak çok üzerine gelindiğinde önemli miktarda kokuyu saldığı bulunmuştur. Ayrıca bu kötü kokunun predatörler tarafindan algılandığında, predatörün kokuyu salgılayan böceğin olduğu bölgeden uzaklaşmasında başarılı olduğu ve hatta avcıların kokulu böcekleri gördüğünde dahi bölgeden kaçındıkları saptanmıştır. Bu duruma ek olarak, avcıların bu kötü koku salan böcekleri çiğnemeleri, ağızlarında hoş olmayan tat ile birlikte uzun süren bir acı oluşmasına neden olmuştur (Krall ve ark. 1999).

Bu çalışmada gözlemlenen durumda ise; $M$. spinosula pentatomidi, aynı beslenme kabında kaldıkları $L$. dispar larvalarını tehdit olarak algılayıp kimyasal yaymış ve 
larvalar da kimyasalın etkisiyle ölmüş olabilir. Diğer bir yandan, M. spinosula'nın fitofag özelliği bulunmasına rağmen türün bireyinin $L$. dispar larvaları üzerinden beslenmiş olma olasılığı da bulunmaktadır. $M$. spinosula'nın biyolojisi hakkında literatürde fazla bilgi bulunmamaktadır. Türün ait olduğu Pentatominae altfamilyası ve Halyini tribe'ına ait bazı türler predatör özellik göstermektir (Rider 2015). Bazı predatör pentatomid türlerinin tükürük bezlerindeki sıvıları kullanıp avlarını hızlı bir şekilde paralize ederek ölümlerine neden oldukları ve geriye kurumuş halde vücut örtüsü kaldığı bilinmektedir (Martinez ve ark. 2014; Hyodo ve ark. 2014). Larvaların ölü hallerinin katılaşmış bir görüntüye sahip olması ve kap içerisinde vücut sıvısı lekelerinin görülmesi de bu tezleri destekleyebilir. Larvaların ölüm nedenlerinin, $M$. spinosula'nın salgıladığı kimyasalın etkisiyle mi yoksa predatör

\section{Kaynaklar}

1. Alford, D.V. 2012. Pests of Ornamental Trees, Shrubs and Flowers: A Colour Handbook. CRC Press, Boca Raton (FL), $480 \mathrm{~s}$.

2. Bayram, Ş. \& Kara K. 1998. Türkiye Tachinidae (Diptera) faunası için yeni bir kayıt Erycia fasciata Villeneuve 1924. Türkiye Entolomoji Dergisi, 22(3): 217-224

3. Baytaş, A. 2008. Türkiye'nin kelebekleri: Doğa rehberi, NTV Yayınları, İstanbul.

4. BRC, Biological Records Centre - Database of insects and their food plants. 2011. http://www.brc.ac.uk/dbif/ (Erişim: Eylül 2016).

5. Brown, J.W., Robinson, G. \& Powell, J.A. 2008. Food plant database of the leaf rollers of the world (Lepidoptera: Tortricidae). $\quad$ Version 1.0. http://www.tortricid.net/foodplants.asp (Erişim: Eylül 2016).

6. Clark, B.R. \& Faeth, S.H. 1998. The evolution of egg clustering in butterflies: a test of the egg desiccation hypothesis. Evolutionary Ecology, 12(5): 543-552.

7. Fauna Europaea. 2014. Version 2.6. http://www.faunaeur.org

8. Ford, T.H., Shaw, M.R. \& Robertson, D.M. 2000. Further host records of some west Palaearctic Tachinidae (Diptera). Entomologist's Record and Journal of Variation, 112(1): 25-36.

9. GOERT - Garry Oak Ecosystems Recovery Team. 2003. Invasive species in Garry oak and associated ecosystems in British Columbia. Victoria (BC). http://www.goert.ca/publications_resources/invasive_spec ies.php (Erişim: Eylül 2016).

10. Herting, B., 1960. Biologie der Westpaläarktischen Raupenfliegen (Diptera: Tachinidae). Monographien zur angewandten Entomologie, 16: 1-188, Berlin.

11. Hyodo, D., Himuro, C. \& Fujisaki, K. 2014. Prey size affects the costs and benefits of group predation in nymphs of the predatory stink bug Andrallus spinidens (Heteroptera: Pentatomidae). Journal of Ethology, 32(3): 173-178. davranışı nedeniyle mi olduğunu belirlemek için yeni gözlemler ile tekrar edilmesi gereklidir. $L$. dispar larvaları laboratuvar gözlemlerine göre oldukça obur ve dayanıklı larvalardır. Besin kalitesi sebebiyle ölme olasılıkları az denebilir. L. dispar, yüksek polifaglık özelliği göstermesi ile birlikte ekonomik önemi olan bir zararlıdır. Bu zararlıya yönelik yapılabilecek biyolojik mücadele çalışmalarında parazitoidlerle birlikte pentatomidlerin de kullanılma olasılığı olabilir.

\section{Teşekkür}

$\mathrm{Bu}$ çalışmada kullanılan bulguların bir kısmı birinci yazarın yüksek lisans tezinin bir bölümüdür. Tür tanımlamaları ve katkıları için Doç. Dr. Yusuf Katılmış (Cynipidae), Doç. Dr. Meral Fent (Pentatomidae) ve Prof. Dr. Kenan Kara’ya (Tachinidae) teşekkür ederiz.

12. Joyner, K. \& Gould, F. 1985. Developmental consequences of cannibalism in Heliothis zea (Lepidoptera: Noctuidae). Annals of the Entomological Society of America, 78: 24-28.

13. Kakimoto, T., Fujisaki, K. \& Miyatake, T. 2003. Egg laying preference, larval dispersion and cannibalism in Helicoverpa armigera (Lepidoptera: Noctuidae), Annals of the Entomological Society of America. 96(6): 793-798.

14. Kanat, M. \& Akbulut, S. 2005. Determination of some pest insect species damaging oak forests in the south east Anatolia region (Kahramanmaraş) of Turkey. Science and Engineering, 8(2): 70-73.

15. Katılmıs, Y. \& Kıyak, S. 2011. Further study on Periclistus brandtii (Ratzeburg, 1831) (Hymenoptera, Cynipidae) from Turkey. Entomological News, 122(1): 51-54.

16. Katılmış, Y. \& Azmaz, M. 2015. Investigation on the inquilines (Hymenoptera: Cynipidae, Synergini) of oak galls from inner western Anatolia, Turkey. Turkish Journal of Zoology, 39(1): 168-173.

17. Krall, B.S., Bartelt, R.J., Lewis, C.J. \& Whitman, D.W. 1999. Chemical defense in the stink bug Cosmopepla bimaculata. Journal of Chemical Ecology, 25(11): 2477 2494.

18. Kuussaari, M., Van Nouhuys, S., Hellmann, J.J., \& Singer, M.C. 2004. Larval biology of checkerspots, Pp. 138-160. In: Ehrlich, P. R. \& Hanski, I. (eds). On the Wings of Checkerspots: A Model System for Population Biology. Oxford University Press, Oxford and New York, 408 p.

19. Lechowicz, M.J. \& Mauffette, Y. 1986. Host preferences of the gypsy moth in eastern North American versus European forests. Revue d'Entomologie du Québec, 31(1): 43-51

20. Lodos, N., Önder, F., Pehlivan E., Atalay, R., Erkin, E., Karsavuran, Y., Tezcan, S. \& Aksoy, S. 1998. Faunistic Studies on Pentatomoidea: (Plataspidae, Acanthosomatidae, Cydnidae, Scutelleridae, Pentatomidae) of Western Black Sea, Central Anatolia and Mediterranean Regions of Turkey. Ege University Press, İzmir, $75 \mathrm{~s}$.

21. Martínez, L.C., do Carmo Queiroz Fialho, M., Zanuncio, J.C. \& Serrão, J.E. 2014. Ultrastructure and cytochemistry 
of salivary glands of the predator Podisus nigrispinus (Hemiptera: Pentatomidae). Protoplasma, 251(3): 535543.

22. Meijerman, L. \& Ulenberg, S.A. 2000. Arthropods of economic Importance: Eurasian Tortricidae. World Biodiversity Database. http://wbd.etibioinformatics.nl/bis/index.php (Erişim: Eylül 2016)

23. Molet, T. 2012. CPHST Pest Datasheet for Lymantria dispar asiatica. USDA-APHIS -PPQ-CPHST.

24. Özdemir, M., Özdemir, Y., Seven, S. \& Bozkurt, V. 2005. Orta Anadolu Bölgesinde Kültür Bitkilerinde Zararlı Tortricidae (Lepidoptera) Faunası Üzerine Araştırmalar. Bitki Koruma Bülteni, 45(1-4): 17-44.

25. Penzes, Z., Tang, C.T., Bihari, P., Bozso, M., Schweger, S. \& Melika, G. 2012. Oak Associated Inquilines (Hymenoptera, Cynipidae, Synergini). Tiscia Monograph Series Volume 11, Szeged, $76 \mathrm{~s}$.

26. Polat, A. \& Tozlu, G. 2010. Erzurum'da Archips rosana (Linnaeus, 1758) (Lepidoptera: Tortricidae)'nın k1sa biyolojisi, konukçuları ve parazitoidleri üzerinde araştırmalar, Türkiye Entomoloji Dergisi, 34(4): 529-542.

27. Richardson, M.L., Mitchell, R.F., Reagel, P.E. \& Hanks, L.M. 2010. Causes and consequences of cannibalism in non-carnivorous insects. Annual Review of Entomology, 55: $39-53$

28. Rider, D.A. 2015. Pentatomoidea Home page. North Dakota State University. https://www.ndsu.edu/faculty/rider/Pentatomoidea/ (Erişim: Eylül 2016).

29. Robinson, G.S., Ackery, P.R., Kitching, I.J., Beccaloni, G.W. \& Hernández, L.M. 2010. HOSTS - A database of the world's lepidopteran host plants, Natural History Museum, London. http://www.nhm.ac.uk/hosts (Erişim: Eylül 2016).

30. Ronquist, F. 1994. Evolution of parasitism among closely related species: phylogenetic relationships and the origin of inquilinism in gallwasps (Hymenoptera, Cynipidae). Evolution, 48(2): 241-266.

31. Schoonhoven, L.M., Van Loon, J.J. \& Dicke, M. 2005. Insect-Plant Biology. 2nd edn, Oxford University Press, Oxford, $440 \mathrm{p}$.

32. Shorthouse, J.D. 1973. The insect community associated with galls of Diplolepis polita (Hym.: Cynipidae). Quaestiones Entomologica, 9: 55-98.
33. Shorthouse, J.D. 1993. Adaptations of gall wasps of the genus Diplolepis (Hym.: Cynipidae) and the role of gall anatomy in cynipid systematics. Memoirs of the Entomological Society of Canada, 165: 139-163.

34. Shorthouse, J.D. \& Leggo, J.J. 2002. Immature stages of the galler Diplolepis triforma (Hymenoptera: Cynipidae) with comments on the role of its prepupae. Canadian Entomologist, 134: 433-446.

35. Skuhravá, M., Skuhravy, V. \& Massa, B. 2007. Gall midges (Diptera: Cecidomyiidae) of Sicily. Naturalista Siciliano, 31: 261-309.

36. Smirnoff, W.A. 1967. Effects of some plant juices on the ugly-nest caterpillar, Archips cerasivoranus, infected with microsporidia. Journal of Invertebrate Pathology, 9: 26-29.

37. Stam, J.M., Kroes, A., Li, Y., Gols, R., Van Loon, J.J., Poelman, E.H. \& Dicke, M. 2014: Plant interactions with multiple insect herbivores: from community to genes. Annual Review of Plant Biology, 65: 689-713.

38. Sullivan, M., MacKinnon, D., Price, T., Biggs, A.R. \& Blue, D. 2011. Stone Fruit Commodity-based Survey Reference. Cooperative Agricultural Pest Survey.

39. Tolman, T. 1997. Butterflies of Britain and Europe. Harpercollins Pub Limited, London.

40. Tunca, H., Kılınçer, N. \& Özkan, C. 2011. Bitkiler, Herbivorlar ve Doğal Düşmanlar Arasındaki Trofik İlişkiler, Ankara Üniversitesi Çevrebilimleri Dergisi, 3(2) 37-45.

41. Van Nouhuys, S. \& Hanski, I. 2004. Natural enemies of checkerspots, Pp. 161-180. In: Ehrlich, P. R. \& Hanski, I. (eds). On the Wings of Checkerspots: A Model System for Population Biology. Oxford University Press, Oxford and New York, 408 p.

42. Wahlberg, N., Kullberg, J., Hanski, I. 2001. Natural history of some Siberian Melitaeini butterfly species (Melitaeini: Nymphalidae) and their parasitoids. Entomologica Fennica, 12(2): 72-77.

43. Wang, X.G. \& Daane, K.M. 2014. Cannibalism of parasitoid-attacked conspecifics in a non-carnivorous caterpillar. Entomologia Experimentalis et Applicata, 151(2): 112-121. 